IJ§ER

ISSN: 2149-5939
International Journal of Social Sciences and Education Research

Online, http://dergipark.gov.tr/ijsser

Volume: 3(1), 2017

\title{
Structuring achievement goal orientation through group problem solving activities ${ }^{1}$
}

\author{
Kian Wah Liew ${ }^{2}$ \\ Grace Lee Ching Yap ${ }^{3}$ \\ Rohaizan Osman ${ }^{4}$ \\ Betsy Guat Poh Lee ${ }^{5}$ \\ Wing Loon Chee ${ }^{6}$
}

\begin{abstract}
Received Date: 01 / 09 / 2016
Accepted Date: 15 / 12 / 2016

Abstract

Achievement goal theory (AGT) has emerged as a prominent framework to examine influences on students' motivation and achievement. The achievement goals are classified into mastery and performance goals orientation. Whilst mastery goals focus on self-improvement and emphasize on learning, performance goals are motivated by a desire for extrinsic approval and may lead to surface learning. This project focuses on creating a learning environment that is students-centered via incorporating AGT within the students' learning curve and examine students' satisfaction in learning and their performance due to these interventions. As the conventional grading system can be a stumbling block, this research employs grouping strategy that sets the classroom with the collaborative learning environment to promote the development of mastery goal orientation and intrinsic motivation. Various pedagogies suited for the encouragement of a mastery goal orientation have been applied. Surveys via the tools adapted from Patterns of Adaptive Learning Survey (PALS), observational data, and interviews are used to study the effect of the goal structure and the learning outcomes.
\end{abstract}

Keywords: Achievement goal theory, mastery goal, performance goal, group work

\section{Introduction}

Since the mid-1980s, AGT has become one of the most prominent theories of motivation in educational psychology. This theory spotlights two major goals, mastery goal and performance goal (Ames \& Archer, 1987). While a mastery goal oriented learner aims to develop one's competence, the performance-goal oriented learners aims to demostrate one's competence by outperforming others (Ames \& Archer, 1988). Mastery goal oriented learners tend to perceive ability as a malleable entity (Dweck, 1986; Thompson \& Musket, 2005). With deep-learning strategy, they do not give up easily when they encounter failures. Comparatively, students who are driven by performance goal have the tendency to avoid challenging tasks. They are associated with the surface learning strategies (Meece et al.,1988; Archer,1994) and they are prone to have negative feeling following poor performances (Elliot \& Dweck, 1988). Elliot \& Harackiewicz (1996) proposed to further partition these two goals into four subclasses based on the effort to

\footnotetext{
${ }^{1}$ This paper was presented in the 2nd ICSSER conference on 4th Nov 2016 in Istanbul, Turkey.

${ }^{2}$ KianWah.Liew@nottingham.edu.my

${ }^{3}$ Grace.Yap@nottingham.edu.my

${ }^{4}$ Rohaizan.Osman@ nottingham.edu.my

${ }^{5}$ Betsy.Lee@ nottingham.edu.my

${ }^{6}$ WingLoon.Chee@nottingham.edu.my
} 
Liew, K.W., Yap, G.L.C., Osman, R., Lee, B.G.P., Chee, W.L. (2017). Structuring achievement goal orientation through group problem solving activities.. International Journal of Social Sciences and Education Research, 3(1), 208-217.

pursue or to avoid the goals. These subclasses are the mastery-approach (i.e., aiming to improve oneself), mastery-avoidance (i.e., aiming to avoid decline in skill), performance-approach (i.e., aiming to outperform others), and performance-avoidance (i.e., aiming not to perform worse than others). Most of the researchers agreed that in general, the mastery goal is more productive than the performance goal, and in terms of the work strategy, the approach form (working to pursue) is more productive than the avoidance form (working to avoid) (Brophy, 2005).

Nonetheless, there were findings that support the performance goal orientation. It was pointed out by Hulleman et.al. (2010) that the students with mastery goal orientation seldom perform better than the ones with performance goal orientation. These four subclasses have been associated with many observable attributes that allow classification of learners based on the expressions of their traits. PALS is one of such survey tools with items on 5-point Likert scales designed to capture these adaptive and maladaptive patterns of learners (Midgley et.al., 2000).

Understanding the role of students' goal orientation is important for engineering education, where conceptual understanding is essential. We are concerned of the learning in mathematics modules at the foundation year as they serve as a "gateway" to engineering. Yusof and Abdul Rahman (2001) reported that the fresh undergraduates at the University of Technology Malaysia encountered difficulties in learning mathematics. According to their study, the freshmen experience the adaptive impacts due to the teaching and learning cultural differences at the university. They have to adapt to large class teaching setting, abandon their rote learning experience and adjust to university teaching and learning methods that emphasize on independent learning. These difficulties are common issues and they have been observed amongst the first year students at other institutions as well (Briggs, Clark \& Hall, 2012; Bowles et al., 2011). Under these pressures, it is very easy for the students to embrace performance goal as a psychological comfort (Anderman \& Midgley, 1997). The linkage between mathematics anxiety and achievement goals has been established by many researchers, especially at the primary level. It was also shown in Middleton \& Midgley (1997) that both forms of performance goals were predictor of test anxiety in mathematics for the sixth grades whereas Zusho, Pintrich \& Cortina (2005) found that fear of failure in mathematics task is linked to the achievement goals among college students in the US. Useful classroom practices that facilitate mastery goals and reduce mathematics anxiety are discussed in Furner \& Gonzalez-DeHass (2011).

Encouraging a particular goal orientation in engineering education has been actively discussed (Canfield and Zastavker, 2010). However, to our best knowledge, the effect of goal orientation development through group work in learning mathematics has not been quantified objectively. Literature shows that group work can create unique learning experience amongst the team members through problem-solving, teamwork and communications. It builds not only the subject wise knowledge but also the motivation to learn and the development of soft skills implicitly (Pintrich, Conley \& Kempler, 2003). Nevertheless, the success of group work largely relied on the implementation approach. In this study, we aim to examine how goal orientation can be developed through group problem solving, and the impact of the goal orientation in one's learning experience. The implementation of the experiment and the measurement of the outcomes are discussed extensively in the following sections. 
Liew, K.W., Yap, G.L.C., Osman, R., Lee, B.G.P., Chee, W.L. (2017). Structuring achievement goal orientation through group problem solving activities. International Journal of Social Sciences and Education Research, 3(1), 208-217.

\section{Methods}

58 students from the Foundation in Engineering programme at the authors' institution took part in the experiment. These participants come from from 13 countries and they have just completed their high school education. The case study was conducted in a Pre-Calculus class that was conducted in three modes: lecture, problem class and laboratory.

The students were divided into ten groups such that each group consists of four to six members with mixed nationalities and genders. The group work activities were run biweekly during the problem class. The topics of the group work are closely related to the topics taught in the lectures, but the problems are open-ended and more challenging, which require conceptual understanding. A sample of the selected problems can be found in Appendix 1. To avoid the fear of failure, and to stress learning over performance, the group work problems were not graded. Nonetheless, feedback were given at the end of each session to enhance the conceptual understanding.

The outcomes of the pedagogy in promoting a mastery goal orientation is gauged using preand post experiment surveys. The survey tool consists of 22 items adapted from PALS, which reflect the four different patterns of learning due to performance and mastery goal orientations. The items are based on a 5-point Likert scale ranging from Strongly Disagree (1) to Strongly Agree (5). A sample of the survey form can be found in Appendix 2.

Besides, 14 students were randomly selected for a semi-structured, open-ended, in-depth interview. 10 interviewed students are male, and 3 are the international students. Narrative summaries were written based on themes of an existing theoretical framework.

\section{Results and discussion}

\section{Quantitative analysis}

45 completed questionnaires were used in the analysis at the end of the experiment. From the pre-test and post-test responses, 4 latent factors are identified from factor analysis using varimax rotation. These factors are constructed based on the composition of variables (numbers on the questionnaire) as follows:

$$
X_{1}=\{6,7,9,17,18,19\}, X_{2}=\{1,8,16,20\}, X_{3}=\{4,10,12,13,14\}, X_{4}=\{5,15\}
$$

Consistent with the structure of PALS, out of these four factors, two of them measure the distinctive traits of performance goal orientation, and the other two measure the traits of mastery goal orientation. To be exact, $X_{1}$ represents the characteristics of performance goal orientation that desires for extrinsic approval. This is labelled as "Ego". $X_{2}$ represents the traits of a mastery goal orientation that reflects positive motivation and intrinsic enjoyment in the learning process. It is labelled as "Like". $X_{3}$ (Knowledge) represents the desire to attain conceptual understanding, an evidence of the behavioural patterns that go with mastery goal orientation. $X_{4}$ (Drill), on the other hand, reflects the emphasis that a repetitious of learnt skill in necessary in learning process. This is associated with the trait of a performance goal orientation of which routine skill is deemed necessary to out-perform the peers academically. 
Liew, K.W., Yap, G.L.C., Osman, R., Lee, B.G.P., Chee, W.L. (2017). Structuring achievement goal orientation through group problem solving activities.. International Journal of Social Sciences and Education Research, 3(1), 208-217.

The score of each attribute is computed as an average of the responses to the variables within the group. The instrument is considered reliable with the Cronbach alpha statistics shown in Table 1 .

Table 1. Cronbach alpha statistics for the before and after treatment

\begin{tabular}{|l|c|c|}
\hline & Before & After \\
\hline$X_{1}$ & 0.8127 & 0.8790 \\
\hline$X_{2}$ & 0.8329 & 0.8630 \\
\hline$X_{3}$ & 0.6747 & 0.8862 \\
\hline$X_{4}$ & 0.6597 & 0.7283 \\
\hline
\end{tabular}

The effect of the group work problem solving activities is analysed through the responses on these factors before and after the treatment. The mean difference and the results of the Wilcoxon signed-rank test for the responses before and after the experiment are shown in Table 2.

Table 2: Mean difference and the significance test

\begin{tabular}{|c|c|c|}
\hline Attributes & Mean(difference) & $p$-value \\
\hline$X_{1}$ & -0.1519 & 0.2842 \\
\hline$X_{2}$ & -0.1167 & 0.4584 \\
\hline$X_{3}$ & -0.3156 & 0.0601 \\
\hline$X_{4}$ & 0.2667 & 0.0463 \\
\hline
\end{tabular}

It is observed that the changes in attributes after the treatment were not as anticipated. The group work problem solving activities failed to encourage the development of mastery goal orientation. Instead of promoting a collaborative environment to motivate students to focus on understanding, we observe a significant drop in the desire to acquire conceptual understanding amongst the students. Rather, the need of drilling exercises is perceived as more important after the participation in the group work problem solving activities. In other words, students are more concerned of the academic performance. The adverse effect of the group work activities in promoting mastery goal orientation could be due to the time limitation in the implementation (Canfield \& Zastavker, 2010). The experiments were run biweekly for 10 weeks, and we believe that the students have not had sufficient exposure and involvement in serious discussion on the openended problems. Most of the students could not finish solving the problems, and they relied on the feedback given by the faculty. This could be a factor that influenced the students to perceive that they need more repetitious training to build up the skill to answer questions and perform well academically. Furthermore, students are very much affected by the grades, as they are eventually assessed via examination, of which grades play a significant role. As such, the mastery goal orientation could not be successfully encouraged despite the removal of grading element in the group work. The responses of each attribute before and after the experiment are shown in Fig.1. 
Liew, K.W., Yap, G.L.C., Osman, R., Lee, B.G.P., Chee, W.L. (2017). Structuring achievement goal orientation through group problem solving activities. International Journal of Social Sciences and Education Research, 3(1), 208-217.

Fig.1 Scatter plot of the responses on each attribute before and after the experiment
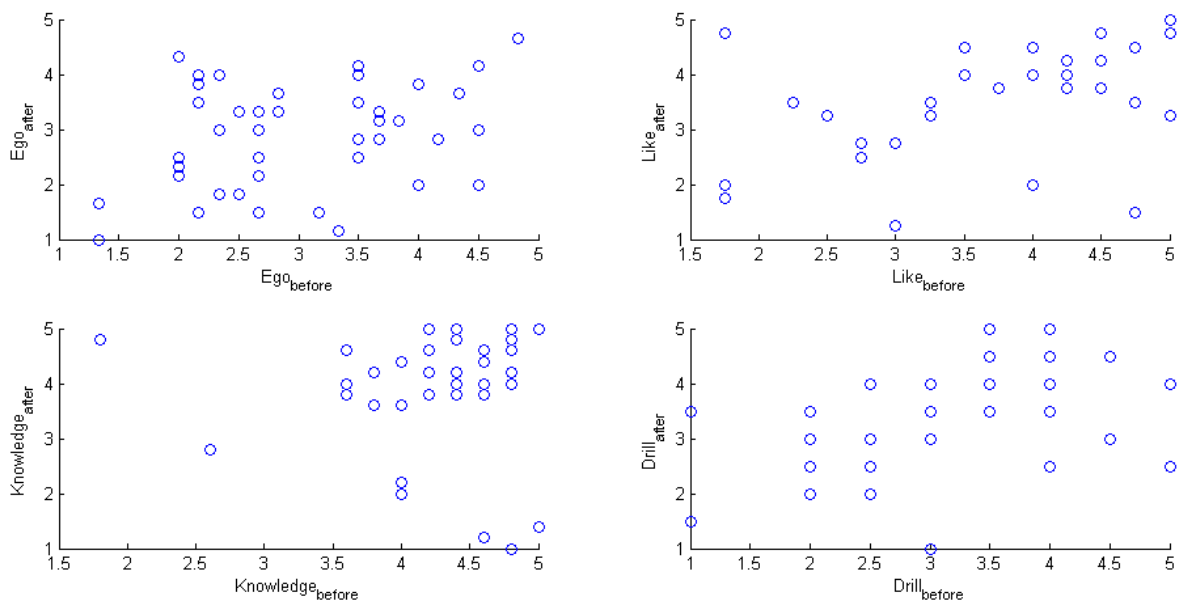

Apart from the goal orientation development, we would like to examine the impact of the goal orientation on the performance in the examination. A regression analysis is performed, of which the exam score is regressed on the factors $\left\{X_{1}, X_{2}, X_{3}, X_{4}\right\}$. The regression model is written in Eq. (1), with the $F$-statistic $=1.7719$ and a $p$-value of 0.1535 .

$$
\text { Score }=52.74+0.43 X_{1}+2.08 X_{2}+4.69 X_{3}-1.29 X_{4}
$$

It is interesting to see that drill $\left(X_{4}\right)$ has a negative coefficient, indicating that an emphasis on drilling exercises has a negative impact on the exam performance. Students working in this direction may perform worse than the peers who do not put the drilling exercises to the foreground. Rather, students who seek for conceptual understanding $\left(X_{3}\right)$ are associated with better grades. Eq. (1) reveals that the mastery goal orientation may increase a student's level of comprehension, and hence leading to a higher grade. Nonetheless, it is possible that students who are adopting the drilling strategy are those who are weak, and they are struggling with the progress in the module. To "survive", these students could not afford to spend time seeking for "understanding".

\section{Qualitative analysis}

An interview session was conducted to gather students' perception on the impact of goal orientations in their learning process. The themes are classified into (i) mathematics anxiety; (ii) the goal orientation in group activities; (iii) the importance of grades; and (iv) the conflict between mastery goal orientation and the assessment structure.

14 interviewees were first being asked about their understanding about mastery and performance goal orientations. Only four students classified themselves as mastery goal oriented learners. All of these students were active participants in the group activities.

\section{(i) Mathematics anxiety}

In our interview, all, except three students, stated that they are not anxious about mathematics classes and the assessments. Two students indicated that they are rather anxious in learning new 
Liew, K.W., Yap, G.L.C., Osman, R., Lee, B.G.P., Chee, W.L. (2017). Structuring achievement goal orientation through group problem solving activities.. International Journal of Social Sciences and Education Research, 3(1), 208-217.

things. The student who is anxious about mathematics stated that it is especially true for the calculus class. He explained, "Maybe I just don't like difficult thing [...] During my secondary school, we had maths and add maths, for add maths I put in a lot of efforts but only get $B+[\ldots]$ Maybe my understanding is not that good [...] By doing more exercises I can catch the way they ask questions [...] When we do more exercises, more or less we will improve."

\section{(ii) Goal orientation in group activities}

All interviewees appreciated group activities. The advantages of the group activities mentioned are: triggering brainstorming, encouraging communication among peers, providing an opportunity to learn from friends. These reflections imply the success of the experiment to promote mastery goal orientation in the classroom through group work problem solving activities. Several interviewees revealed that, "[...] I learn better when I talk to my peers about the concept [...]" Despite the benefit to enhance understanding, students mentioned that attentions need to be given to the implementation of the group activities. Factors such as group size, members with dominant or shy character may hinder group discussion. Besides, a faculty needs to allocate sufficient time for the group activities to encourage effective and thorough discussion. In addition, setting the right level of difficulties in the problems could be a challenge to the faculty as a problem with high complexities may be regarded as challenging and interesting to a group of students; it may be above some students' levels of comprehension, and hence giving an adverse effect in the motivation. One of the interviewee explained that she finds the problems as interesting, but too hard to even strike a starting point: "[...] I think the problem is interesting, but it is too hard for me. I could just listen to the discussion of my peers, and sometimes all of us just couldn't figure out how to solve the problem [...]"

\section{iii) Importance of grades}

Half of the interviewees held the view that ultimately it is grade that matters. According to them, it is not so important even if they do not understand the topic. One of them even has mistaken grade as the factor rather than a results of learning, "[...From] my experience, the people with the high grade, [...], even if they missed some classes, can still catch up". Those students who disagreed that grade is ultimately the most important indicator often derived satisfaction from understanding, for example "[...] when I was in IG, I always found this dissatisfaction that I couldn't really understand." "Even though I get a C, if I have done my best, I wouldn't feel bad about it'.

\section{iv) Conflicts between mastery goal orientation and assessments}

Most interviewees found that there was conflict between adopting mastery goal oriented learning under the current assessments format. The conflict arises from different aspects. For examples, quizzes that were given too frequently in a semester did not allow them to have enough time to fully understand a topic. Questions in the assessment that were routine which did not require higher level thinking also make the time spent in understanding a topic less worthy. On the other hand, the students who adopted mastery goal oriented learning did not see this as a conflict, " [...] if a student has mastered the subject, he would have done well in exam too, although he might not be the best student. [...] a mastery goal oriented student needs some kind of drilling questions too 
Liew, K.W., Yap, G.L.C., Osman, R., Lee, B.G.P., Chee, W.L. (2017). Structuring achievement goal orientation through group problem solving activities. International Journal of Social Sciences and Education Research, 3(1), 208-217.

in order to keep up with familiarity of skills". A student made it clearer by saying "However, drilling is not a mean to gain knowledge, but just to keep up the skill."

\section{Conclusions}

The project is aimed to introduce some new teaching methodologies in class and allow students to gain new experience in learning through grouping with the purpose of providing a good transition from high school to the university. As most of the students were growing up in an environment that promote performance goal oriented learning, the structure of the group activities opened one's eyes to realize the importance of mastery skills and hence promoting the deep learning approach. These students eventually did better in the mathematics module. This is reflected in the regression model, with the knowledge factor giving the most contribution to the assessment score.

Nonetheless, the structure of the group learning gave adverse effect to the group of mediocre students. With the time constraints and peer pressure, this group of students chose to adopt surface learning, hoping that they can perform well in the examination by memorizing the facts or examples. Most of our students fall in this group, and we observe a behavioural change in the factors of "knowledge" and "drill".

Generally, the students felt positive towards the implementation of pedagogy that promote mastery approach oriented teaching. Although some of them did not change their learning patterns after the group activities, the experience they gained from the activities were generally being described as joyful and fruitful. For future study, we need to think of how to structure the group learning to help the mediocre group of students to see the importance of mastery goal orientation. Besides, attention should also be given to the design of assessment measurement so that the grades achieved can reflect a student's deep understanding of a content area.

Human motivation is a vast and complicated subject involving lots of confounding factors and interactions which is rather impossible to be fully analysed in a simple classroom experiment. We do hope researchers and educators in the future will benefit from this report.

\section{Appendix 1}

Three sample problems from the activities are given in the following:

Problem 1

Water is poured into the vase with a capacity of $500 \mathrm{ml}$ at a constant rate of $25 \mathrm{ml} / \mathrm{s}$ until overflow. The height of the water level in the vase, $h$, is a function of time $t$ (in second), sketch the graph of $h$ versus $t$. Your graph should reflect as much information as described in the quetions and the picture as possible. 
Liew, K.W., Yap, G.L.C., Osman, R., Lee, B.G.P., Chee, W.L. (2017). Structuring achievement goal orientation through group problem solving activities.. International Journal of Social Sciences and Education Research, 3(1), 208-217.

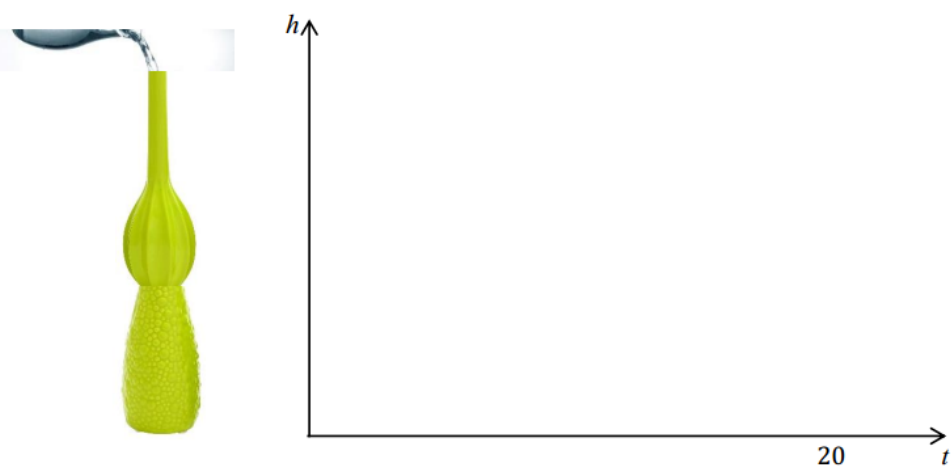

\section{Problem 2}

Based on your knowledge on the graph of $y=\sin x$ and $y=e^{x}$, GUESS and SKETCH the graphs of $y=\sin \left(e^{x}\right)$ and $y=e^{\sin x}$. You need not plot the graph precisely. However, please give the reasoons why you sketch the graphs in the way they look.

Problem 3

Is it true that $0 . \underbrace{999999 \ldots}_{\text {infinitely many } 9}=1$ ?

\section{Appendix 2}

Questions from the Pre-test.

1. An important reason I do my math is because I enjoy it.

2. When I study I put important ideas into my own words.

3. One reason I would not participate in math class is to avoid looking stupid.

4. It is important to me that I improve my skills this year.

5. When I study for a test I practise saying the important facts over and over to myself.

6. One of my main goals is to avoid looking like I can't do my math.

7. Doing better than other students in math class is important to me.

8. I like math even if I make a lot of mistakes in the tests.

9. One of my goals is to show to others that math is easy for me.

10. When I am studying a topic, I try to make everything fits together.

11. I used what I have learned from old homework assignments and the textbook to do new math assignments.

12. When I do my math work, I try to remember what the lecturer said in class so that I can answer the questions correctly.

13. It is important to me that I thoroughly understand my math.

14. When reading, I try to connect the things I am reading with what I have already learnt.

15. When I read the handout/book from the math class, I say the words over and over to myself to help me to remember.

16. An important reason why I do my math problems is because I like to learn new things.

17. One of my goals in math is to avoid looking like I have trouble doing the work.

18. I would feel successful in math if I perform better than most of the other students.

19. One of my goals is to look smart in comparison to the other students in my math class.

20. I like a math problem best when it really makes me think.

21. When I study for a math test I try to remember as many facts as I can.

22. An important reason I do my math work is to avoid embarrassment. 
Liew, K.W., Yap, G.L.C., Osman, R., Lee, B.G.P., Chee, W.L. (2017). Structuring achievement goal orientation through group problem solving activities. International Journal of Social Sciences and Education Research, 3(1), 208-217.

\section{References}

Ames, C., \& Archer, J. (1987). Mothers' beliefs about the role of ability and effort in school learning. Journal of Educational Psychology, 79(4), 409-414

Ames, C., \& Archer, J. (1988). Achievement goals in the classroom: Student's learning strategies and motivation processes. Journal of Educational Psychology, 80(3), 260-267.

Anderman, E. M., \& Midgley, C. (1997). Changes in achievement goal orientations, perceived academic competence, and grades across the transition to middle-level schools. Contemporary Educational Psychology, 22(3), 269-298.

Archer, J., (1994). Achievement goals as a measure of motivation in university students. Contemporary Educational Psychology, 19, 430-446.

Bowles, A., Dobson, A., Fisher, R., \& McPhail, R. (2011). An exploratory investigation into first year student transition to university. In Krause, K., Buckridge, M., Grimmer, C. and Purbrick-Illek, S. (Eds.) Research and Development in Higher Education: Reshaping Higher Education, 34, 61-71.

Briggs, A. R., Clark, J., \& Hall, I. (2012). Building bridges: Understanding student transition to university. Quality in Higher Education, 18(1), 3-21.

Brophy, J. (2005) Goal theorists should move on from performance goals, Educational Psychologist, 40(3), 167-176, DOI: 10.1207/s15326985ep4003_3

Canfield, C., \& Zastavker, Y. V. (2010). Achievement goal theory: A framework for implementing group work and open-ended problem solving. 2010 IEEE Frontiers in Education Conference (Fie).

Dweck, C. S. (1986). Motivational processes affecting learning. American Psychologist, 41(10), 10401048.

Elliot, A. J., \& Harackiewicz, J. M. (1996). Approach and avoidance achievement goals and intrinsic motivation: A mediational analysis. Journal of Personality and Social Psychology, 70(3), 461-475.

Elliot, E.S., \& Dweck,C.S. (1988). Goals: An approach to motivation and achievement. Journal of Personality and Social Psychology, 54, 5-12.

Furner, J. M., \& Gonzalez-DeHass, A. (2011). How do students' mastery and performance goals relate to math anxiety? Eurasia Journal of Mathematics, Science \& Technology Education, 7(4), 227-242.

Hulleman, C. S., Shrager, S. M., Bodmann, S. M., \& Harackiewicz, J. M. (2010). A meta-analytic review of achievement goal measures: Different labels for the same constructs or different constructs with similar labels? Psychological Bulletin, 136(3), 422-449.

Meece, J.L., Blumenfeld, P.C., \& Hoyle, R.K. (1988) Student's goal orientation and cognitive engagement in classroom activities. Journal of Educational Psychology, 80, 514-524.

Middleton, M. J., \& Midgley, C. (1997). Avoiding the demonstration of lack of ability: An underexplored aspect of goal theory. Journal of Educational Psychology, 89, 710-718.

Midgley, C., Maehr, M. L., Hruda, L. Z., Anderman, E., Anderman, L., Freeman, K. E., Gheen, M., Kaplan, A., Kumar, R., Middleton, M. J., Nelson, J., Roeser, R., \& Urdan, T. (2000). PALS: Manual for the Patterns of Adaptive Learning Skills, The University of Michigan.

Nicholls, J. G. (1984). Achievement motivation: Conceptions of ability, subjective experience, task choice and performance. Psychological Reivew, 91(3), 328-346.

Pintrich, P. R. (2000). Multiple goals, multiple pathways: The role of goal orientation in learning and achievement. Journal of Educational Psychology, 92(3), 544-555.

Pintrich, P. R., Conley, A. M., \& Kempler, T. M. (2003). Current issues in achievement goal theory and research. International Journal of Educational Research, 39(4), 319-337. 
Liew, K.W., Yap, G.L.C., Osman, R., Lee, B.G.P., Chee, W.L. (2017). Structuring achievement goal orientation through group problem solving activities.. International Journal of Social Sciences and Education Research, 3(1), 208-217.

Senko, C., Hulleman, C. S., \& Harackiewicz, J. M. (2011). Achievement goal theory at the crossroads: Old controversies, current challenges, and new directions. Educational Psychologist, 46(1), 26-47.

Thompson, T. \& Musket S. (2005). Does priming for mastery goals improve the performance of students with an entity view of ability? British Journal of Educational Psychology, 75(3), 391-409.

Yusof, Y. M., \& Abdul Rahman, R. (2001). Mathematics education at Universiti Teknologi Malaysia (UTM): learning from experience. Jurnal Teknologi E, (34E), 9-24.

Zusho, A., Pintrich, P. R., \& Cortina, K. S. (2005). Motives, goals, and adaptive patterns of performance in Asian American and Anglo American students. Learning and Individual Differences, 15, 141-158 